\title{
An Interesting Case of Penetrating Injury Neck and Face
}

\section{Venkatachalapathy TS*}

Senior Resident, Indira Gandhi Govt General Hospital and Post Graduate Institute, Puducherry, India

\begin{abstract}
Penetrating neck trauma is an important area of trauma care that has undergone evolution in the recent past. A remarkable number of changes have occurred in the treatment paradigm as new technologies have developed and as surgeons have explored the outcomes from different treatment protocols. Therapy has evolved from no treatment (before effective anesthesia and instrumentation), to non operative management, to routine exploration, to selective exploration and adjunctive invasive or noninvasive assessment. Penetrating neck injuries remain challenging, as there are a number of important structures in a small area and injury to any of these structures may not be readily apparent.
\end{abstract}

Keywords: Coconut leaf stem; Penetrating injury; Neck hematoma

\section{Introduction}

Two recent reports demonstrate the importance of the setting in which penetrating neck injuries occur, particularly treatment protocols in combat zones. Sarkar et al. [1], presented 2 cases from Western Baghdad, and Ramasamy et al. [2], performed a retrospective medical record review of British military casualties from Iraq and Afghanistan who sustained penetrating neck injuries to determine the need for pre hospital cervical immobilization, given current ATLS protocols requiring spinal precautions when a significant mechanism of injury may damage the cervical spine. In the study by Ramasamy et al. [2], of 90 patients with a penetrating neck injury, $66(73 \%)$ were from explosions and $24(27 \%)$ were from gunshot wounds. In $20(22 \%)$ patients, cervical spine injuries were present; only $6(7 \%)$ survived to reach the hospital, and 4 of these 6 died within 72 hours of their injuries. Of 56 survivors that reached a surgical facility, only $1(1.8 \%)$ had an unstable cervical spine injury requiring surgical stabilization, and this patient subsequently died due to a concomitant head injury. Penetrating neck trauma represents approximately $5-10 \%$ of all trauma cases that present to the emergency department. About $30 \%$ of these cases are accompanied by injury outside of the neck zones as well.

The current mortality rate in civilians with penetrating neck injuries ranges from 3-6\%. During World War II, the mortality rate was $7 \%$, and, in World War I, it was $11 \%$. Higher mortality rates occur with injuries to large vessels, such as the carotid or sub clavian arteries and veins.

The evaluation of a patient with penetrating neck trauma always should start with advanced trauma life support (ATLS), a paradigm that begins with a directed primary survey emphasizing airway, breathing, and circulation $(\mathrm{ABC})$. After patients are stabilized, they undergo a secondary survey that includes a complete history and a thorough physical examination. These steps, together with the studies discussed in Workup, are used to identify the likely injury complex and to direct further treatment or diagnostic testing.

There is evidence to suggest that the hard signs of airway injury are more reliable and result in less negative operative explorations compared with hard signs of vascular injury. The rate of negative exploration for patients with hard signs of vascular injury varies widely, but it may be estimated at $10 \%$.

\section{Discussion}

A 55 yr old man came with history of fall of coconut leaf stem over left side of face and sustained penetrating injury starting from pre auricular region extending to posterior aspect of neck (Figure $1 \& 2$ ).

On presentation patient was having pain over the injury site with foreign body in situ, his vitals was stable (pulse-80/min, BP- 130/90). Thorough examination of site of injury and facial nerve examination done, there was no evidence of facial nerve injury.

Patient was planned for Computed Tomography scan [3-6] of neck and face to rule out injury to internal jugular vein, external jugular vein and extent of injury to neck muscles in relation to foreign body.

CT scan revealed foreign body superficial to deep cervical fascia and all the major vessels intact, the foreign body situated in the plane superficial to parotid fascia extending into neck. Patient underwent exploration of neck and face under general anesthesia, foreign body extracted and thorough wash given, haemostasis achieved. Patient withstood the procedure and there was no bleeding after the surgery.

Patient was kept under ICU care for monitoring vitals and looking

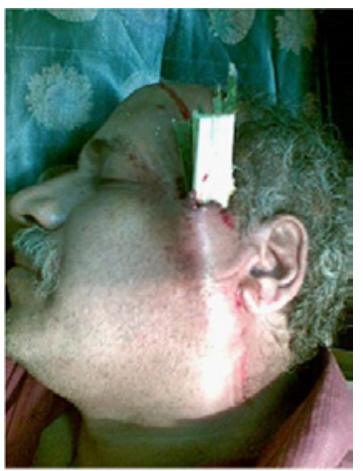

Figure 1: Coconut leaf stem over left side of face.

*Corresponding author: Dr Venkatachalapathy TS, Assistant Professor in Surgery, Devaraj Urs Medical College, Tamaka, Kolar, Karnataka , India, Tel. +918197507094, E-mail: drvenkey@hotmail.com

Received February 03, 2012; Accepted March 21, 2012; Published March 26 2012

Citation: Venkatachalapathy TS (2012) An Interesting Case of Penetrating Injury Neck and Face. J Clinic Case Reports 2:116. doi:10.4172/2165-7920.1000116

Copyright: () 2012 Venkatachalapathy TS. This is an open-access article distributed under the terms of the Creative Commons Attribution License, which permits unrestricted use, distribution, and reproduction in any medium, provided the original author and source are credited. 
Citation: Venkatachalapathy TS (2012) An Interesting Case of Penetrating Injury Neck and Face. J Clinic Case Reports 2:116. doi:10.4172/21657920.1000116

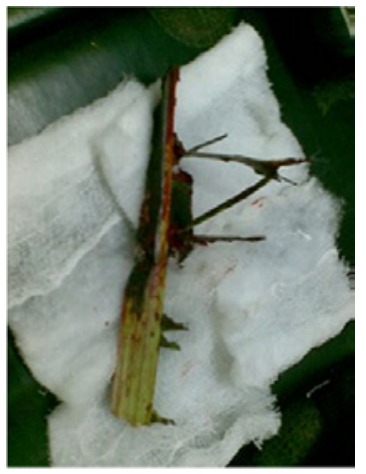

Figure 2: Leaf stem.

for hematoma. He had minimal hematoma neck on the first post op day, for which we planned conservative treatment.

On the second post op day hematoma reduced and patient was evaluated for any injury to facial nerve and parotid duct. Patient was discharged on 7 th post op day.

On follow up after 2 weeks wound has healed well and had minimal collection around pre auricular region, which resolved after 2 days.

\section{Conclusion}

This was rare presentation of penetrating injury without injuring major neck vessels and facial nerve.

\section{References}

1. Breeze J, Gibbons AJ, Shieff C, Banfield G, Bryant DG, et al. (2011) Combatrelated craniofacial and cervical injuries: a 5-year review from the British military. J Trauma 71: 108-113.

2. Carter LM, Wales CJ, Varley I, Telfer MR (2008) Penetrating facial injury from angle grinder use: management and prevention. Head Face Med 4: 1.

3. Mozolewski PJ, Curry JD, Browder T, Fildes J (2001) Computed tomographic scan can be used for surgical decision making in zone II penetrating neck injury. J Trauma 51: 315-319.

4. Sekharan J, Dennis JW, Veldenz HC, Miranda F, Frykberg ER, et al. (2000) Continued experience with physical examination alone for evaluation and management of penetrating zone 2 neck injuries: results of 145 cases. J Vasc Surg 32: 483-489.

5. Biffl WL, Moore EE, Rehse DH, Offner PJ, Franciose RJ, et al. (1997) Selective management of penetrating neck trauma based on cervical level of injury. Am J Surg 174: 678-682.

6. Rizzo AG, Steinberg SM, Flint LM (1995) Prospective Assessment of the value of computed tomography for trauma. J Trauma 38: 338-342. 